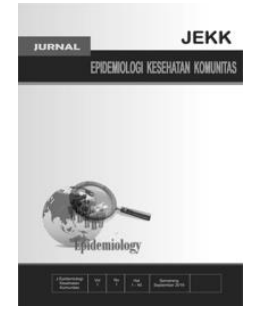

\title{
Optimasi Kualitas Citra Radiografi Abdomen Berdasarkan Body Mass Index dan Tegangan Tabung pada Computed Radiography
}

\author{
Siti Rosidah*, Ari Soewondo**, M. Sakundarno Adi** \\ *Mahasiswa Pascasarjana Epidemiologi Universitas Diponegoro, **Fakultas Kedokteran Universitas \\ Diponegoro
}

\begin{abstract}
Background: Computed Radiography is a modality of radiographic processing that has wideexposure latitude. Radiographic examination with CR modality is less concerned with the accuracy of the exposure factor especially in the use of tube voltage that can affect the image quality. Image quality determines the accuracy of an illlness diagnosis. Abdominal examination is often done in the radiological installation of hospital, with different patient conditions especially in Body Mass Index (BMI) the use of tube voltages tends too vary, so that affect the quality of radiograph and patient's received dose.

Methods: This type of research is analytical observational with cross sectional design. Samples in thus research amounted to 108 distributed in each group of Body Mass Index (underweight, normal, overweight) respectively 36 samples. Each Body Mass Index group sample is taken from the use of tube voltages that are often used in hospital $75 \mathrm{kV}, 80 \mathrm{kV}, 85 \mathrm{kV}$ and $90 \mathrm{kV}$ respectively as much as 9. Assessments include the value of the exposure index, noise and anatomical information. Statistical data analysis with Spearman test and univariat.

Result: There is a significant connection between the use of cylinder voltage with an index exposure, noise and anatomical imagery. The use of cylinder voltage in aech Body Mass Index group effects the score of exposure index. The higher cylinder voltage that is used in each Body Mass Index group, the exposure index will have higher score.
\end{abstract}

Conclusion : Optimised tube voltage for BMI under $75 \mathrm{kV}$, normal BMI $80 \mathrm{kV}$ and BMI over $85 \mathrm{kV}$

Keywords: computed radiography; tube voltage; Body Mass Index

*Penulis korespondensi, rosidah.siti@ymail.com 


\section{Pendahuluan}

Nyeri abdomen merupakan keluhan umum pasien di sebagian besar pusat pelayanan kesehatan. Angka prevalensi nyeri abdomen antara 22\%-28\%. Di Amerika serikat 5-10\% pasien mengalami kasus nyeri abdomen dari semua kasus yang ada. Nyeri pada abdomen bisa dibedakan menjadi 2 kategor yaitu nyeri abdomen akut dan abdomen kronis. Pada kasus abdomen akut harus segera dilakukan penanganan. ${ }^{11}$

Untuk menegakkan diagnosa pada kasus abdomen akut bisa dilakukan dengan pemeriksaan radiologi foto abdomen. Pemeriksaan radiologi adalah pemeriksaan dengan memanfaatkan sinar-X untuk menampakkan objek yang diperiksa melalui pembuatan radiograf yang memberikan informasi diagnostik sebanyak-banyaknya. ${ }^{4}$

Kecanggihan teknologi pencitraan digital untuk diagnostik telah diaplikasikan dalam pelayanan diagnostik imejing di Rumah Sakit. Salah satunya adalah penggunaan Computed Radiography (CR). Computed Radiography (CR) adalah sistem akuisisi dan pemrosesan citra digital untuk memproduksi radiograf statis. CR dikembangkan pada tahun 1981 oleh Fuji Corporation, dengan aplikasi klinis pertama di tahun 1983. Sistem ini menggunakan tabung sinar-X standar dan generator namun memerlukan reseptor gambar khusus dan pengolahan citra dengan sistem komputerisasi yang terdiri dari penerima citra, perangkat pembaca gambar dan sebuah workstation. Pada Computed Radiography hasil citra yang dihasilkan dapat dimanipulasi karena dalam bentuk citra digital. ${ }^{14}$

Citra digital merupakan perubahan dari gambar analog menuju gambar digital, yang diproses secara digital sehingga memungkinkan untuk dilakukan manipulasi gambar. Fungsi dari pengolahan citra digital untuk memproses data yang mempunyai informasi yang cocok untuk proses komputer dan untuk memperbaiki kualitas citra. ${ }^{6}$

Kualitas citra merupakan suatu syarat untuk menunjukkan ketepatan atau representasi dari bagian anatomi pasien dalam radiograf. Suatu citra yang dapat menunjukkan struktur dan jaringan lunak secara jelas dikatakan citra yang memiliki kualitas yang baik. Sedangkan citra dikatakan memiliki kualitas yang buruk apabila berisi gambar yang sulit diferensiasi dengan mata manusia. Kualitas gambar (image quality) yang optimal dengan citra kuantitatif membantu keakuratan dalam mendiagnosa, sehingga dapat menghindari kesalahan dalam diagnose. $^{19}$ Dokter spesialis radiologi memerlukan radiograf yang memiliki kualitas baik agar dapat menegakkan diagnosa secara tepat. ${ }^{6}$ Kualitas radiograf dipengaruhi oleh tegangan tabung dan filtrasi, sedangkan kuantitas radiograf dipengaruhi oleh tegangan tabung, kuat arus dan waktu, Focus Film Distance (FFD), ketebalan obyek dan filtrasi. ${ }^{6}$ Menurut Bontrager faktor yang digunakan untuk mengevaluasi kualitas citra digital adalah brighness, contrast, resulution, distortion, noise dan Exposure Index (EI). ${ }^{4}$

Exposure Index (EI) adalah ukuran dari jumlah pemaparan yang diterima oleh reseptor gambar (IR). Dokter spesialis radiologi dan radiografer menggunakan standar Exposure Index sebagai standar optimal pemaparan yang diterima oleh IR. Nilai Exposure index pada pesawat CR memiliki rentang yang bervariasi. Pada Computed Radiography (CR) merk Carestream/ kodak nilai EI yang bisa diterima pada rentang 1000-2000. ${ }^{20}$ Berdasarkan penelitian Dwi Rochmayanti untuk mendapatkan gambar yang optimal pada pemeriksaan abdomen diperlukan nilai Exposure index sebesar $1725 .^{15}$

Berdasarkan studi pendahuluan dari beberapa Rumah Sakit yang menggunakan sistem pengolahan Computed Radiography Carestram, pada pemeriksaan abdomen memiliki nilai Exposure Index yang berbeda pada rentang 908-1777. Salah satu faktor yang menentukan nilai Exposure Index adalah faktor eksposi dan ketebalan obyek atau Body Mass Index. Tegangan tabung menjadi komponen yang lebih sering diubah-ubah dengan arus tabung relatif tetap. Penelitian sebelumnya juga menunjukkan pemakaian faktor eksposi di instalasi radiologi memiliki rentang yang panjang dan hasil penelitian menunjukkan untuk mendapatkan radiograf berkualitas dan pararan radiasi sekecil mungkin faktor eksposi dapat dioptimalkan. ${ }^{12}$ Berdasarkan latar belakang tersebut penulis tertarik melakukan 
penelitian untuk mengetahui hubungan pemakaian tabung terhadap index exposure, noise dan anatomi citra pada setiap kelompok Body Mass Index.

\section{Metode}

Jenis penelitian ini adalah penelitian observasional analitik dengan rancangan penelitian cross sectional. Penelitian dilakukan dengan melakukan observasi pada pemeriksaan radiografi abdomen proyeksi AP dengan pengolahan citra digital computed radiography periode bulan April-Juni 2019. Melakukan pencatatan mengenai data pasien pemeriksaan radiologi abdomen yang meliputi nama pasien, nomor register, pemakaian faktor eksposi (tegangan tabung) dan nilai indeks eksposure yang tertera pada layar Computed Radiography sesuai nomor registrasi pasien. Serta menghitung BMI setiap sampel.

Data yang sudah didapatkan kemudian dikelompokkan sesuai dengan tiga kategori Body Mass Indeks (Underweight pada nilai BMI <18,5, normal dengan nilai BMI 18,524,99 dan overweight dengan nilai BMI > 25). Data penelitian pada setiap kategori Body Mass Index dikelompokkan kembali berdasarkan pemakaian tegangan tabung yang sering digunakan di RS $(75 \mathrm{kV}, 80 \mathrm{kV}, 85 \mathrm{kV}$ dan 90 $\mathrm{kV})$. Penilaian nilai informasi anatomi dilakukan dengan cara responden menilai kejelasan gambaran anatomi musculus spoas line, columna vertebrae dan tulang pelvis. Penilaian tingkat noise dilakukan oleh setiap responden menilai citra hasil pemeriksaan foto abdomen proyeksi AP. Untuk menguji kesesuaian pendapat ketiga responden (uji interobserver) dilakukan dengan uji Kappa. Apabila diperoleh hasil lebih besar dari $75 \%$ ( $\mathrm{K}>$ 0,75), maka uji kappa dikatakan sempurna.

Dilakukan uji normalitas data dengan menggunakan uji Kolmogorof smirnov, untuk menentukan jenis analisis statistik yang digunakan. Apabila data hasil uji Kolmogorov smirnov ( $p$-value > 0.05), maka data penelitian berdistribusi normal dan sebaliknya. Untuk mengetahui hubungan pemakaian tabung terhadap index exposure, noise dan anatomi citra pada setiap kelompok Body Mass Index dilakukan dengan pengujian statistik spearman. Dari uji spearman diharapkan dapat mengetahui signifikasi hubungan, kuat hubungan derta arah atau jenis hubungan. Untuk mendapatkan faktor eksposi yang sesuai dengan hasil radiograf yang optimal, maka dilakukan analisis dari hasil uji univariat.

\section{Hasil}

\section{Analisa Kesesuaian antar Observer}

Analisis kesesuaian antar observer dilakukan terhadap penilaian tiga responden yang menilai informasi anatomi dan noise pada citra radiografi abdomen proyeksi AP dengan pengolahan computed radiography. Penilaian menggunakan skala likert Analisis kesesuaian penilaian antar observer dilakukan dengan uji Kappa dengan hasil ditunjukan pada Tabel 1.

Tabel 1. Analisis Kesesuaian antar Observer

\begin{tabular}{llcc}
\hline No & \multicolumn{1}{c}{ Observer } & $\mathrm{K}$ & Keterangan \\
\hline \multirow{2}{*}{1} & $\begin{array}{l}\text { Observer 1 } \\
\text { dengan } \\
\text { Observer 2 }\end{array}$ & 0,914 & \\
\hline \multirow{2}{*}{2} & $\begin{array}{l}\text { Observer 1 } \\
\text { dengan } \\
\text { Observer 3 }\end{array}$ & 0,954 & Sempurna \\
\hline \multirow{2}{*}{3} & $\begin{array}{l}\text { Observer 2 } \\
\text { dengan } \\
\text { Observer 3 }\end{array}$ & 0,893 & \\
\hline
\end{tabular}

Hasil uji Kappa terhadap penilaian informasi anatomi dan noise pada citra radiografi abdomen proyeksi AP dengan pengolahan computed radiography menunjukkan kesesuaian jawaban ketiga observer memiliki nilai $\mathrm{K}>0,75$ dengan taraf kesesuaian sempurna.

\section{Analisa Univariat}

Penilaian pada masing-masing variabel menggunakan cara yang berbeda. Data exposure index diperoleh dari nilai yang tercantum pada monitor perangkat CR. Penilaian noise dan informasi anatomi dilakukan oleh tiga radiografer senior sebagai observer dengan menggunakan skala likert. Pada penilaian informasi anatomi, setiap observer menilai citra organ yang ada pada abdomen antara lain musculus spoas line, 
columna vertebrae dan tulang pelvis. Skor 1 artinya organ tidak tampak, skor 2 artinya organ tampak kurang jelas dan skor 3 artinya organ tampak jelas. Selanjutnya skor penilaian dijumlahkan untuk masing-masing perlakuan pada setiap sampel. Pada penilaian noise observer menilai tingkat noise yang terdapat pada radiograf Abdomen. Skor 1 artinya terdapat banyak noise pada radiograf, skor 2 artinya terdapat noise namun tidak mengganggu citra, dan skor 3 artinya tidak ada noise pada radiograf yang mengganggu citra. Hasil analisis univariat meliputi nilai mean, standar deviasi, nilai minimal, maksimal dan median pada variabel yang dinilai dalam penelitian ini tercantum pada Tabel 2.

Tabel 2. Hasil Analisis Univariat

\begin{tabular}{|c|c|c|c|c|}
\hline Kelompok BMI & $\begin{array}{c}\text { Tegangan } \\
\text { Tabung }\end{array}$ & Indeks Exposure & Noise & $\begin{array}{c}\text { Informasi } \\
\text { Anatomi }\end{array}$ \\
\hline \multirow[t]{4}{*}{ BMI underweight } & $75 \mathrm{kV}$ & $\begin{array}{l}1307,33 \pm 118,682 ; 1130-1458 \\
1252\end{array}$ & $\begin{array}{l}1,4067 \pm 0,46495 ; 1-2 ; \\
1,33\end{array}$ & $\begin{array}{l}8,3333 \pm 0,86603 ; 7- \\
9 ; 9\end{array}$ \\
\hline & $80 \mathrm{kV}$ & $\begin{array}{l}1709,89 \pm 26,474 ; 1680- \\
1769 ; 1701\end{array}$ & $\begin{array}{l}1,1111 \pm 0,3333 ; \quad 1-2 ; \\
1\end{array}$ & $\begin{array}{l}8,6667 \pm 0,70711 ; 7- \\
9 ; 9\end{array}$ \\
\hline & $85 \mathrm{kV}$ & $\begin{array}{l}1578,67 \pm 76,664 ; 1501-1715 \\
1550\end{array}$ & $1,00 \pm 0,00$ & $\begin{array}{l}8,6327 \pm 0,3333 ; 8-9 \\
9\end{array}$ \\
\hline & $90 \mathrm{kV}$ & $\begin{array}{l}1791,56 \pm 13,268 ; 1760-1805 \\
1795\end{array}$ & $1,00 \pm 0,00$ & $\begin{array}{l}8,7778 \pm 0,44096 ; 8- \\
9 ; 9\end{array}$ \\
\hline \multirow[t]{4}{*}{ BMI normal } & $75 \mathrm{kV}$ & $\begin{array}{l}1280 \pm 116,320 ; 1128-1478 \\
1305\end{array}$ & $\begin{array}{l}2,1111 \pm 0,92796 ; 1-3 ; \\
2\end{array}$ & $\begin{array}{l}5,7778 \pm 2,72845 ; 3- \\
9 ; 7\end{array}$ \\
\hline & $80 \mathrm{kV}$ & $\begin{array}{l}1454,56 \pm 87,484 ; 1302-1554 \\
1475\end{array}$ & $\begin{array}{l}1,2222 \pm 0,44096 ; 1-2 \\
1\end{array}$ & $\begin{array}{l}8,3333 \pm 1,32288 ; 6- \\
9 ; 9\end{array}$ \\
\hline & $85 \mathrm{kV}$ & $\begin{array}{l}1553 \pm 156,868 ; 1168-1658 ; \\
1596\end{array}$ & $\begin{array}{l}1,1111 \pm 0,333333 ; 1- \\
2 ; 1\end{array}$ & $\begin{array}{l}8,6667 \pm 1,0000 ; 6-9 \\
9\end{array}$ \\
\hline & $90 \mathrm{kV}$ & $\begin{array}{l}1630,67 \pm 56,383 ; 1546-1696 ; \\
1650\end{array}$ & $1,00 \pm 0,00$ & $9 ; 9$ \\
\hline \multirow[t]{4}{*}{ BMI overweight } & $75 \mathrm{kV}$ & $\begin{array}{l}1163,44 \pm 67,881073-1273 \\
1141\end{array}$ & $\begin{array}{l}2,7778 \pm 0,44096 ; 2-3 ; \\
3\end{array}$ & $\begin{array}{l}3,6667 \pm 1,0000 ; 3-6 \\
3\end{array}$ \\
\hline & $80 \mathrm{kV}$ & $\begin{array}{l}1223,67 \pm 75,715 ; 1045-1280 \\
1256\end{array}$ & $\begin{array}{l}2,3333 \pm 0,50000 ; 2-3 ; \\
2\end{array}$ & $\begin{array}{l}4,5556 \pm 1,3333 ; 3-6 ; \\
5\end{array}$ \\
\hline & $85 \mathrm{kV}$ & $\begin{array}{l}1424,11 \pm 82,517 ; 1315-1540 \\
1420\end{array}$ & $\begin{array}{l}1,2222 \pm 0,44096 ; 1- \\
2 ; 1\end{array}$ & $\begin{array}{l}8,4444 \pm 1,13039 ; 6- \\
9 ; 9\end{array}$ \\
\hline & $90 \mathrm{kV}$ & $\begin{array}{l}1627,33 \pm 80,366 ; 1520-1723 \\
1638\end{array}$ & $1,1111 \pm 0,3333 ; 1-2 ; 1$ & $\begin{array}{l}8,7778 \pm 0,66667 ; 7- \\
9 ; 9\end{array}$ \\
\hline
\end{tabular}

Tabel 2 menunjukkan hasil penilaian variabel penelitian yang menunjukkan pada kelompok BMI underweight nilai exposure index terendah sebesar 1130 pada pemakaian tegangan tabung $75 \mathrm{kV}$ dan tertinggi sebesar 1805 pada pemakaian tegangan tabung $90 \mathrm{kV}$. Sedangkan nilai noise pada tegangan tabung 75 $\mathrm{kV}$ dan $80 \mathrm{kV}$ masih terdapat noise sebesar 12, dan pada pemakaian tegangan tabung $90 \mathrm{kV}$ nilai noise konstan 1 yang berarti tidak terdapat noise pada radiograf. Penilaian informasi anatomi menunjukkan nilai terendah pada nilai sebesar 7 dan tertinggi pada penggunaan sebesar 9, dengan nilai mean 9. Pada kelompok BMI normal nilai exposure index terendah sebesar 1128 pada pemakaian tegangan tabung $75 \mathrm{kV}$ dan tertinggi sebesar 1696 pada pemakaian tegangan tabung $90 \mathrm{kV}$. Nilai Noise dan informasi anatomi pada $90 \mathrm{kV}$ konstan sebesar 1 yang berarti semakin tidak ada noise dan diikuti dengan nilai informasi anatomi 9 yang berarti gambar sangat jelas. Penilaian informasi anatomi menunjukkan nilai terendah pada nilai sebesar 3 pada pemakain tegangan 
tabung $75 \mathrm{kV}$ dan tertinggi memiliki nilai 9 pada pemakaian $90 \mathrm{kV}$. Pada kelompok BMI overweight nilai exposure index terendah sebesar 1073 pada pemakaian tegangan tabung $75 \mathrm{kV}$ dan tertinggi sebesar 1723 pada pemakaian tegangan tabung $90 \mathrm{kV}$. Sedangkan nilai noise pada tegangan tabung $75 \mathrm{kV}$ dan 80 $\mathrm{kV}$ terdapat pada rentang 2-3, serta pada tegangan tabung $85 \mathrm{kV}$ dan $90 \mathrm{kV}$ nilai noise terdapat pada rentang 1-2. Penilaian informasi anatomi menunjukkan nilai terendah pada nilai sebesar 3 dan tertinggi pada penggunaan sebesar 9 dengan informasi terbaik pada $85 \mathrm{kV}$ dan $90 \mathrm{kV}$. Pemakaian tegangan tabung pada setiap kelompok Body Mass Index berpengaruh terhadap nilai exposure index. Semakin tinggi nilai tegangan tabung yang digunakan pada setiap kelompok Body Mass Index semakin tinggi pula nilai exposure index.

\section{Nilai Tegangan Tabung yang Mampu Memberikan Kualitas Citra Radiografi Abdomen Optimum pada Kelompok Body Mass Index}

Penentuan nilai tegangan tabung yang mampu mereduksi noise, menghasilkan informasi anatomi, dan kualitas citra yang optimal dilakukan dengan menganalisis hasil uji univariat sesuai tabel 2. Dari data tersebut kita bisa melihat pemakaian tegangan tabung terhadap exposure index, noise maupun informasi anatomi pada setiap kelompok BMI. Tegangan yang dipilih adalah nilai tegangan minimal yang mampu menghasilkan informasi anatomi optimal dan noise rendah dengan mempertimbangkan dosis radiasi yang diterima pasien serendah mungkin tanpa mengurangi nilai diagnostik.

\section{Pemakaian Tegangan Tabung pada Kelompok BMI Underweight}

Pada Tabel 2 hasil analisis univariat dapat kita lihat uji univariat pada setiap kelompok BMI. Pada kelompok BMI underweight pemakaian tegangan tabung $75 \mathrm{kV}, 80 \mathrm{kV}$, $85 \mathrm{kV}$ dan $90 \mathrm{kV}$ dengan $25 \mathrm{mAs}$ menghasilkan nilai exposure index pada rentang 1130 sampai 1805 yang masih pada batas toleransi. Untuk noise dan informasi anatomi dapat kita lihat semakin tinggi tegangan tabung yang digunakan diikuti dengan penurunan noise dan peningkatan informasi anatomi. Kualitas radiograf yang baik adalah mampu memberikan informasi diagnostik dengan memperhatikan dosis radiasi yang diterima pasien seminimal mungkin. Pada kelompok BMI underweight ini kualitas gambar yang paling baik dapat kita lihat pada pemakaian tegangan tabung $85 \mathrm{kV}$ dan $90 \mathrm{kV}$ karena memiliki nilai noise paling rendah dan informasi anatomi yang tinggi. Akan tetapi jika dikaitkan dengan citra maupun dosis kepada pasien, pemakaian tegangan tabung $75 \mathrm{kV}$ sudah mampu memberikan informasi anatomi yang baik dengan dosis minimal. Hal ini dapat dilihat dari nilai noise rata rata 1,4 dan informasi anatomi rata rata 8,3 yang berarti masih terdapat noise tetapi tidak mengganggu informasi citra.

\section{Pemakaian Tegangan Tabung pada Kelompok BMI Normal}

Pada Tabel 2 hasil analisis univariat dapat kita lihat uji univariat pada setiap kelompok BMI. Pada kelompok BMI normal pemakaian tegangan tabung $75 \mathrm{kV}, 80 \mathrm{kV}, 85 \mathrm{kV}$ dan $90 \mathrm{kV}$ dengan $25 \mathrm{mAs}$ menghasilkan nilai exposure index pada rentang 1128 sampai 1696 yang masih pada batas toleransi. Untuk noise dan informasi anatomi dapat kita lihat semakin tinggi tegangan tabung yang digunakan diikuti dengan penurunan noise dan peningkatan informasi anatomi. Kualitas radiograf yang baik adalah mampu memberikan informasi diagnostik dengan memperhatikan dosis radiasi yang diterima pasien seminimal mungkin. Pada kelompok BMI normal ini kualitas gambar yang paling baik dapat kita lihat pada pemakaian tegangan tabung $90 \mathrm{kV}$ karena memiliki nilai noise paling rendah dan informasi anatomi yang paling tinggi. Akan tetapi, jika dikaitkan dengan citra maupun dosis ke pasien, pada pemakaian tegangan tabung $75 \mathrm{kV}$ belum mampu memberikan informasi anatomi yang baik karena pada pemakaian tegangan tabung ini masih terdapat nilai noise yang tinggi dan informasi anatomi yang rendah. Pada pemakaian tegangan tabung $80 \mathrm{kV}$ nilai noise mengalami penurunan dan informasi citra meningkat Hal ini dapat dilihat dari nilai noise rata rata 1,2 dan informasi anatomi rata rata 8,3 yang berarti masih 
terdapat noise tetapi tidak mengganggu informasi citra.

\section{Pemakaian Tegangan Tabung pada Kelompok BMI Overweight}

Pada Tabel 2 hasil analisis univariat dapat kita lihat uji univariat pada setiap kelompok BMI. Pada kelompok BMI overweight pemakaian tegangan tabung $75 \mathrm{kV}, 80 \mathrm{kV}$, $85 \mathrm{kV}$ dan $90 \mathrm{kV}$ dengan $25 \mathrm{mAs}$ menghasilkan nilai exposure index pada rentang 1073 sampai 1723 yang masih pada batas toleransi. Untuk noise dan informasi anatomi dapat kita lihat semakin tinggi tegangan tabung yang digunakan diikuti dengan penurunan noise dan peningkatan informasi anatomi. Kualitas radiograf yang baik adalah mampu memberikan informasi diagnostik dengan memperhatikan dosis radiasi yang diterima pasien seminimal mungkin. Pada kelompok BMI overweight ini kualitas gambar yang paling baik dapat kita lihat pada pemakaian tegangan tabung $90 \mathrm{kV}$ karena memiliki nilai noise paling rendah dan informasi anatomi yang tinggi. Akan tetapi jika kita kaitkan dengan citra maupun dosis ke pasien, pada pemakaian tegangan tabung $75 \mathrm{kV}$ dan $80 \mathrm{kV}$ belum mampu memberikan informasi anatomi yang baik dengan dosis minimal. Hal ini dapat dilihat masih terdapat citra yang memiliki nilai noise tinggi dan informasi anatomi rendah yang berarti gambar yang dihasilkan terdapat banyak noise yang mengganggu citra. Pada pemakaian tegangan tabung $85 \mathrm{kV}$ nilai noise mengalami penurunan dan informasi citra meningkat $\mathrm{Hal}$ ini dapat dilihat dari nilai noise rata rata 1,2 dan informasi anatomi rata rata 8,4 yang berarti masih terdapat noise tetapi tidak mengganggu informasi citra.

\section{Pembahasan}

Penentuan nilai tegangan tabung yang mampu memberikan kualitas citra optimal pada radiografi Abdomen Proyeksi AP menggunakan pengolahan computed radiography carestream dilakukan dengan melakukan analisis hasil uji univariat pada semua kelompok Body Mass Index. Penelitian ini mencoba mencari nilai tegangan tabung yang sesuai untuk menghasilkan kualitas citra yang optimal pada pemeriksaan abdomen proyeksi AP dengan pengolahan computed radiography di kelompok BMI underweight, normal dan overweight dengan memperhatikan prinsip optimalisasi proteksi radiasi. Penentuan kesesuaian pemakaian tegangan tabung pada setiap kelompok BMI dilakukan dengan melakukan analisis setiap kenaikan tegangan tabung dengan nilai exposure index, noise maupun informasi citra anatomi dengan memperhatikan dosis ke pasien.

Pada kelompok BMI underweight sesuai Tabel 2 setiap perubahan pemakaian tegangan tabung dari $75 \mathrm{kV}$ ke $80 \mathrm{kV}, 85 \mathrm{kV}$ maupun 90 $\mathrm{kV}$ terjadi kenaikan perubahan nilai exposure index dan informasi anatomi. Sedangkan perubahan kenaikan pemakaian tegangan tabung terhadap nilai noise mengalami penurunan. Kualitas radiograf yang baik adalah mampu memberikan informasi diagnostik dengan memperhatikan dosis radiasi yang diterima pasien seminimal mungkin. Pada kelompok BMI underweight kualitas gambar yang paling baik terdapat pada pemakaian tegangan tabung $85 \mathrm{kV}$ dan $90 \mathrm{kV}$ karena memiliki nilai noise paling rendah dan informasi anatomi yang tinggi. Akan tetapi, jika dikaitkan dengan citra maupun dosis ke pasien, pada pemakaian tegangan tabung $75 \mathrm{kV}$ sudah mampu memberikan informasi anatomi yang baik dengan dosis minimal. Hal ini dapat dilihat dari nilai noise rata rata 1,4 dan informasi anatomi rata rata 8,3 yang berarti masih terdapat noise tetapi tidak mengganggu informasi citra.

Pengaruh perubahan tegangan tabung terhadap kualitas citra pada kelompok BMI normal sesuai Tabel 2 pada kelompok BMI normal pemakaian tegangan tabung $75 \mathrm{kV}$, $80 \mathrm{kV}, 85 \mathrm{kV}$ dan $90 \mathrm{kV}$ dengan $25 \mathrm{mAs}$ menghasilkan nilai indeks eksposure pada rentang 1128 sampai 1696 yang masih pada batas toleransi. Untuk noise dan informasi anatomi dapat kita lihat semakin tinggi tegangan tabung yang digunakan diikuti dengan penurunan noise dan peningkatan informasi anatomi. Kualitas radiograf yang baik adalah mampu memberikan informasi diagnostik dengan memperhatikan dosis radiasi yang diterima pasien seminimal mungkin. Pada kelompok BMI normal ini kualitas gambar 
yang paling baik dapat kita lihat pada pemakaian tegangan tabung $90 \mathrm{kV}$ karena memiliki nilai noise paling rendah dan informasi anatomi yang paling tinggi. Akan tetapi jika kita kaitkan dengan citra maupun dosis ke pasien, pada pemakaian tegangan tabung $75 \mathrm{kV}$ belum mampu memberikan informasi anatomi yang baik karena pada pemakaian tegangan tabung ini masih terdapat nilai noise yang tinggi dan informasi anatomi yang rendah. Pada pemakaian tegangan tabung $80 \mathrm{kV}$ nilai noise mengalami penurunan dan informasi citra meningkat Hal ini dapat dilihat dari nilai noise memiliki rata-rata 1,2 dan informasi anatomi memiliki rata-rata 8,3 yang berarti masih terdapat noise tetapi tidak mengganggu informasi citra. Dengan demikian, pada kelompok BMI normal untuk menghasilkan kualitas citra optimal dengan dosis minimum bisa menggunakan tegangan tabung $80 \mathrm{kV}$.

Sedangkan, pada kelompok BMI overweight pemakaian tegangan tabung $75 \mathrm{kV}$, $80 \mathrm{kV}, 85 \mathrm{kV}$ dan $90 \mathrm{kV}$ dengan $25 \mathrm{mAs}$ menghasilkan nilai exposure index pada rentang 1073 sampai 1723 yang masih pada batas toleransi. Untuk noise dan informasi anatomi dapat kita lihat semakin tinggi tegangan tabung yang digunakan diikuti dengan penurunan noise dan peningkatan informasi anatomi. Kualitas radiograf yang baik adalah mampu memberikan informasi diagnostik dengan memperhatikan dosis radiasi yang diterima pasien seminimal mungkin. Pada kelompok BMI overweight ini kualitas gambar yang paling baik dapat kita lihat pada pemakaian tegangan tabung $90 \mathrm{kV}$ karena memiliki nilai noise paling rendah dan informasi anatomi yang tinggi. Akan tetapi jika kita kaitkan dengan citra maupun dosis ke pasien, pada pemakaian tegangan tabung $75 \mathrm{kV}$ dan $80 \mathrm{kV}$ belum mampu memberikan informasi anatomi yang baik dengan dosis minimal. Hal ini dapat dilihat masih terdapat citra yang memiliki nilai noise tinggi dan informasi anatomi rendah yang berarti gambar yang dihasilkan terdapat banyak noise yang mengganggu citra. Pada pemakaian tegangan tabung $85 \mathrm{kV}$ nilai noise mengalami penurunan dan informasi citra meningkat. Hal ini dapat dilihat dari nilai noise memiliki rata rata 1,2 dan informasi anatomi memiliki rata-rata 8,4 yang berarti masih terdapat noise tetapi tidak mengganggu informasi citra. Sehingga, tegangan tabung $85 \mathrm{k} \mathrm{V}$ bisa digunakan pada pada pemeriksaan radiografi abdomen kelompok BMI overweight untuk menghasilkan citra yang optimum dengan dosis radiasi ke pasien minimum. Pemakaian faktor eksposi sesuai BMI sudah dapat memberikan kualitas gambar yang optimal.

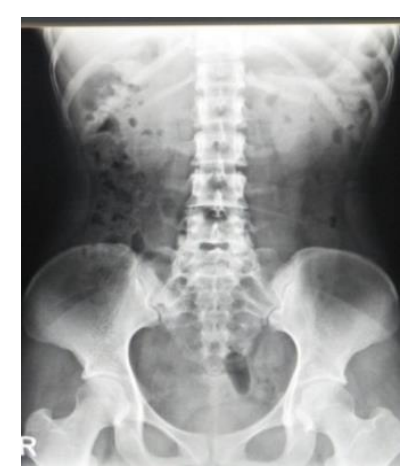

Gambar 1. Radiograf Abdomen kelompok BMI underweight dengan tegangan tabung $75 \mathrm{kV}$

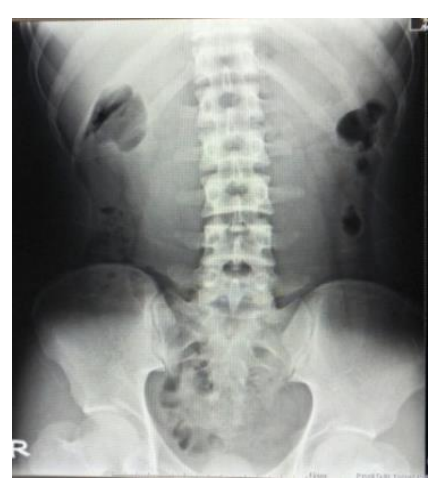

Gambar 2. Radiograf Abdomen kelompok BMI normal dengan tegangan tabung $80 \mathrm{kV}$ 


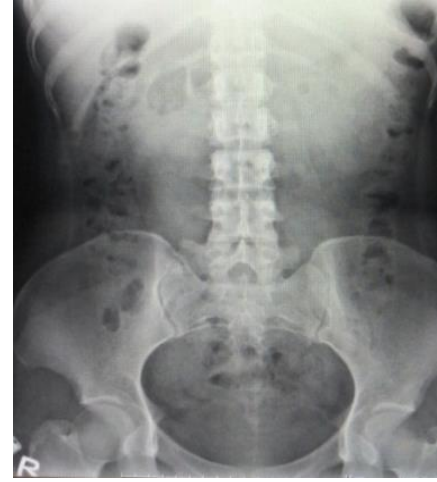

Gambar 3. Radiograf Abdomen kelompok BMI overweight dengan tegangan tabung $85 \mathrm{kV}$

Hasil penelitian tersebut sejalan dengan penelitian sebelumnya yang melakukan penelitian hubungan ketebalan anatomi terhadap faktor eksposi dengan hasil ada hubungan positiv antara $\mathrm{kVp}, \mathrm{mAs}$ dan ketebalan anatomi pada hanpir semua pemeriksaa, penurunan ketebalan obyek diikuti dengan penurunan faktor exposi. ${ }^{11}$ Selain itu penelitian ini juga sejalan dengan penelitian sebelumnya yang bertujuan mennetukan ketepatan faktor eksposi untuk pemeriksaan thorak dewasa dan anak, dari hasil penelitian faktor eksposi yang sering digunakan di lapangan bisa lebih ditekan untuk menghasilkan radiograf optimum dan dosis pasien yang minimum. ${ }^{18}$ Penggunaan tegangan tabung pada pemeriksaan radiografi sebaiknya disesuaikan dengan kondisi/ obyek yang diperiksa.

\section{Kesimpulan}

Kualitas citra yang optimum dengan radiasi yang rendah pada kelompok BMI underweight bisa dilakukan dengan pemakaian $25 \mathrm{mAs}$ pada tegangan tabung $75 \mathrm{kV}$, kelompok BMI normal $80 \mathrm{kV}$ dan kelompok BMI overweight menggunakan $85 \mathrm{kV}$.

\section{Daftar Pustaka}

1. Adejoh, T., Ewuzie, O.C., Ogbonna, J.K., Nwefuru, S.O. and Onuegbu, N.C. 2016. A Derived Exposure Chart for Computed Radiography in a Negroid Population. Health, 8 , 953-958. http://dx.doi.org/10.4236/health.2016.8100 81

2. American Association of Physicists in Medicine. 2009. An Exposure Indicator for Digital Radiography. Retrieved from http://www.aapm.org/pubs/reports/RPT_1 16.pdf.

3. Ballinger, Philip W. dan Eugene D, Frank. 2003. Merril's Atlas of Radiographich positions and Radiologic Prosedures, Tenth Edition, Volome three. Saint Louis : Mosby.

4. Bontranger, Knneth L. dan John P. Lampignano. 2010. Textbook of Radiographic Positioning and Related Anatomy, Seventh Edition. Saint Louis : Mosby.

5. Bontranger, Knneth L. dan John P. Lampignano. 2014. Textbook of Radiographic Positioning and Related Anatomy, Eight Edition. Saint Louis : Mosby.

6. Bushong, Steward C. 2013. Radiologic Science for Technologists, Physics, Biology and Protection. Saint Louis : Mosby.

7. Fahmi A. 2017. Pengaruh Faktor Eksposi Pada Pemerikasaan Abdomen Terhadap Kualitas Radiograf Dan Paparan Radiasi Menggunakan Computed Radiography, Journal Undip Berkala Fisika, 11(4): 109118

8. Hiswara, Eri, 2015, Buku Pintar Proteksi dan Keselamatan Radiasi di Rumah Sakit, BATAN Press : Jakarta.

9. Jacqueline G. 2010. The Concept of Exposure Index For Carestream Irectview Systems, Carestream Health, Inc.U.S.A.2010.

10. Kwasi O. 2016. Relationship between Patient Anatomical Thickness and Radiographic Exposure Factors for Selected Radiologic Examinations, Journal of Health, Medicine and Nursing, An International Peer-reviewed Journal, 23. 
11. Mervyn, Chohen D, Richard M, Jeanne H, Walter H, Paul B, dan Bruce A. 2011. A Comparison Study of Radiographic Exposure for Neonatal Chest Radiographs at 4 Academic Hospitals. American Journal Roentgenology.

12. Moore CS, Wood TJ, Beavis AW, Saunderson JR. 2013.Correlation of the clinical and physical image quality in chest radiography for average adults with a computed radiography imaging system. $\mathrm{Br}$ J Radiol, 86:20130077.

13. Papp, J. 2011. Quality Management In The Imaging Sciences, Fourth Edition. Saint Louis : Mosby.

14. Rochmayanti, D. 2016. Implementation of exposure index for optimize image quality and patient dose estimation with computed radiography (a clinical study of adult posteroanterior chest and anteroposterior abdomen radiography, Journal Physic Conference Series, 2019.

15. Sisnawati. 2015. Pengaruh Variasi $k V$ Terhadap Noise Citra Lumbosacral Lateral Pada Penggunaan Computer Radiography (Studi Eksperimen Pada Phantom). Semarang : Prodi D III Teknik Radiodiagnostik dan Radioterapi Politeknik Kesehatan Kemenkes Semarang.

16. Steven D, Bruce R, Lois J, dan Bruce K. 2012. New Exposure Indicators for Digital Radiography Simplified for Radiologists and Technologists. American Journal Roentgenology.

17. Ursula M. 2013. Retrospective evaluation of exposure index (EI) values from plain radiographs reveals important considerations for quality improvement Journal of Medical Radiation Sciences 60: 115-122. 